\title{
p300 gene alterations in intestinal and diffuse types of gastric carcinoma
}

\author{
Naoki Koshishi ${ }^{1,2}$, Ja-Mun Chong ${ }^{3}$, Tomoki Fukasawa ${ }^{1,2}$, Rie Ikeno ${ }^{1}$, Yukiko Hayashi ${ }^{4}$, Nobuaki Funata ${ }^{4}$, \\ Hideo Nagai ${ }^{5}$, Michiko Miyaki ${ }^{4}$, Yoshiro Matsumoto ${ }^{2}$, and Masashi Fukayama ${ }^{3}$ \\ ${ }^{1}$ Department of Pathology, Jichi Medical School, Tochigi, Japan \\ ${ }^{2}$ Department of Surgery, Yamanashi Medical University, Yamanashi, Japan \\ ${ }^{3}$ Department of Pathology, Graduate School of Medicine, University of Tokyo, 7-3-1 Hongo, Bunkyo-ku, Tokyo 113-0033, Japan \\ ${ }^{4}$ Department of Pathology, Tokyo Metropolitan Komagome Hospital, Tokyo, Japan \\ ${ }^{5}$ Department of Surgery, Jichi Medical School, Tochigi, Japan
}

\begin{abstract}
Background. 300 is a transcriptional coactivator, and biallelic mutations of the $p 300$ gene have been demonstrated in human cancers.

Methods. In 80 gastric carcinoma tissues, loss of heterozygosity (LOH) was analyzed by polymerase chain reaction (PCR) analysis, using 14 primer pairs at the 22q11-13 locus containing NF2 and p300. The mutations of the p300 gene were examined by reverse transcriptase-PCR (RT-PCR) and single-stranded conformation polymorphism (SSCP) analysis. Results. LOH was frequently observed at the $22 q 13$ locus containing the $p 300$ gene in gastric carcinomas, with an equal frequency in the intestinal (21/34) and diffuse (30/46) types. However, LOH was significantly correlated with advanced stage and lymph node metastasis only in the intestinal type. Using RT-PCR-SSCP analysis, mutations of the p300 gene were identified in the intestinal $(6 / 15)$ and in the diffuse $(4 / 18)$ types, but all of the mutations were accompanied by $\mathrm{LOH}$ at the $22 q 13$ locus only in the intestinal type.

Conclusion. The $\mathbf{p 3 0 0}$ gene behaves as a tumor suppressor gene in the intestinal, but not in the diffuse type of gastric carcinoma. The significance of frequent gene alteration in the diffuse type should be further investigated by the clarification of other mechanisms of $\mathbf{p 3 0 0}$ inactivation and by clarification or of the functional role of $p 300$ in cell adhesion/spreading.
\end{abstract}

Key words $p 300$ - Chromosome $22 \mathrm{q} \cdot$ Gastric carcinoma . Tumor suppressor gene $\cdot$ Loss of heterozygosity

\section{Introduction}

Gastric carcinoma shares common chromosomal losses with colorectal carcinoma, such as that of $5 \mathrm{q}(30 \%$ to $40 \%$ at or near $A P C$ ), $17 \mathrm{p}$ (over $60 \%$ at $T P 53$ ), and $18 \mathrm{q}$ (over $60 \%$ at $D C C$ ) [1]. Loss of heterozygosity $(\mathrm{LOH})$

Offprint requests to: M. Fukayama

Received: August 29, 2003 / Accepted: February 3, 2004 on chromosome $22 \mathrm{q}$ was also observed in both carcinomas [2,3], but the involved gene has not yet been clarified. Candidate suppressor genes on chromosome 22q are the neurofibromatosis 2 (NF2) gene [4] and the p300 gene [5]. NF2 encodes a 595-amino-acid protein, schwannomin or merlin (moesin-ezrin-radixin-likeprotein), which exhibits significant homology to a highly conserved family of proteins involved in connecting the cytoskelton to components of plasma membranes. NF2 is considered to be a tumor suppressor gene for tumors associated with NF2 disorders (schwannoma and meningioma) and for NF2-unrelated tumors (mesothelioma, colon cancer, and gastrointestinal stromal tumor) [6-8]. On the other hand, $p 300$ is a transcriptional coactivator that facilitates gene expression through several mechanisms [9], including molecular scaffolds coupling many transcriptional factors [10], chromatin remodeling by histone acetyltransferase (HAT) activity [11], and activation of transcription factors, such as $p 53$ and GATA1, by acetylation (FAT activity) [12]. p300 is a target for the adenoviral E1A oncoprotein, and bi-allelic mutations have been demonstrated in some human cancers, including colorectal carcinomas [13,14]. Furthermore, in regard to its highly homologous protein, CBP (cAMP response element binding profein [CREB]-binding protein), it is known that patients with one mutant germline copy of CBP develop a rare, multisystem disorder, Rubinstein Taybi syndrome, one of the characteristics of which is a heightened cancer risk [15]. In the present study, we focused on the alterations on chromosome 22q to clarify its significance in the development and progression of gastric carcinoma. Detailed mapping of $\mathrm{LOH}$ and subsequent polymerase chain reaction (PCR)-single-stranded conformation polymorphism (SSCP) analysis demonstrated that p300 gene alteration occurs frequently in gastric carcinoma. However, the significance of the abnormalities is different in the intestinal and diffuse types of gastric carcinoma. Each subtype of gastric carcinoma exhibits 
its own clinicopathological features and is considered to develop through a different genetic pathway [1].

\section{Patients, materials, and methods}

\section{Tumor samples}

Tumor samples consisted of 60 advanced (invasion in and beyond the muscular layer) and 20 early gastric carcinomas (intramucosal carcinoma or invasion of the submucosal layer), which were resected from 80 patients at Tokyo Metropolitan Komagome Hospital and Jichi Medical School Hospital. The corresponding normal tissues, which were located at a site remote from the carcinoma, were also obtained simultaneously. All samples were taken immediately after resection and frozen in dry ice-hexane. The resected stomach was then routinely processed with hematoxylin-eosin staining for histopathological analysis. Tumor location, depth of invasion, and lymphatic or vascular invasion were determined with reference to the Japanese classification of gastric carcinoma of the Japanese Research Society for Gastric Cancer [16]. Histological subtypes of the gastric carcinoma were classified as diffuse type or intestinal type, using Laurén's criteria [17]. The presence of Epstein-Barr virus (EBV) was determined by an in situ hybridization (ISH) method targeting EBVencoded small RNA (EBER) [18], using formalinfixed paraffin-embedded sections of the carcinoma.

\section{LOH analysis using microsatellite markers}

High-molecular weight DNA was extracted from frozen tissues, using phenol-chloroform extraction, as reported previously [19]. The DNA was then subjected to the PCR-based analyses, as described below. PCR-based analysis of $\mathrm{LOH}$ was performed using microsatellite markers. The primers targeted 14 microsatellites; D22S264 (22q11), D22S446 (22q11), D22S315 (22q1112), D22S300 (22q12), NF2CA3 (22q12), D22S268 (22q12), D22S275 (22q12), D22S280 (22q12), D22S304 (22q12-13), D22S277 (22q13), IL2RB (22q12-13), D22S423 (22q13), D22S279 (22q13), and D22S274 (22q13). The sequences of the primers were obtained from the Genome Database (http://www.gdb.org/gdb/) and Ensembl Human (http://www.ensembl.org/ Homo_sapiens/) on the Internet. PCR was performed under the same conditions as those outlined in a previous study [18]. The reaction product was then denatured and electrophoresed on a $6 \%$ polyacrylamide gel containing $7 \mathrm{M}$ urea. The gel was exposed to X-ray film for $48-72 \mathrm{~h}$ at $-80^{\circ} \mathrm{C}$. By comparing the electrophoresis patterns of the PCR products of the paired DNA samples of the same patient, $\mathrm{LOH}$ was defined as the loss of any band for the normal tissue in the tumor sample.

\section{Reverse transcriptase-PCR (RT-PCR) and $R T$-PCR-SSCP}

Total RNA was extracted, using the acid guanidium method, from 33 advanced gastric carcinomas and five normal tissues of the stomach mucosa. All carcinomas were advanced ones, because of the limitation of the amount of the tissue available for RNA study. Isolated RNA was reverse-transcribed to cDNA, using the Ready To GO kit (Amersham Pharmacia Biotech, Uppsala, Sweden). The coding region of the $p 300$ gene between codons 111 and 1832 (71\% of the p300 gene) was divided into 16 regions, each of which was amplified by each specific primer pair, as described previously [13]. Then, the amplified products were separated overnight at $6-8 \mathrm{~W}$ on $6 \%$ non-denaturing polyacrylamide gels containing $6 \%$ glycerol.

\section{Sequencing analysis}

The shifted bands were excised from the SSCP gel and subjected to DNA extraction. The extracted DNA was amplified by PCR, using the same conditions as for the RT-PCR-SSCP. DNA sequencing of PCR products was carried out using an ABI PRISM TM dRhodamine Terminator Cycle Sequencing Ready Reaction Kit (Applied Biosystems, Chiba, Japan) and an ABI PRISM TM 377 DNA Sequencer.

\section{Statistical analysis}

Statistical analysis was performed using Fisher's exact probability test, the $\chi^{2}$ test for independence, the Kruskal-Wallis rank test, and the Mann-Whitney $U$ test. A $P$ value of $<0.05$ was considered significant.

\section{Results}

\section{PCR evaluation of LOH using microsatellite markers}

Fourteen microsatellite markers were first used to evaluate the $\mathrm{LOH}$ on chromosome arm $22 \mathrm{q}$ in gastric carcinoma. Sixty cases of advanced gastric carcinoma (36 diffuse type and 24 intestinal type) were examined, because only a limited amount of DNA was available from the early carcinomas.

All of these microsatellite loci showed LOH at various frequencies (Fig. 1), but the loci that showed LOH of more than 30\% were D22S275 (14 of 43 informative cases; 33\%), D22S277 (21/59; 36\%), D22S304 (21/56; $38 \%)$, and IL2RB $(27 / 59 ; 46 \%)$. Thus, the most fre- 


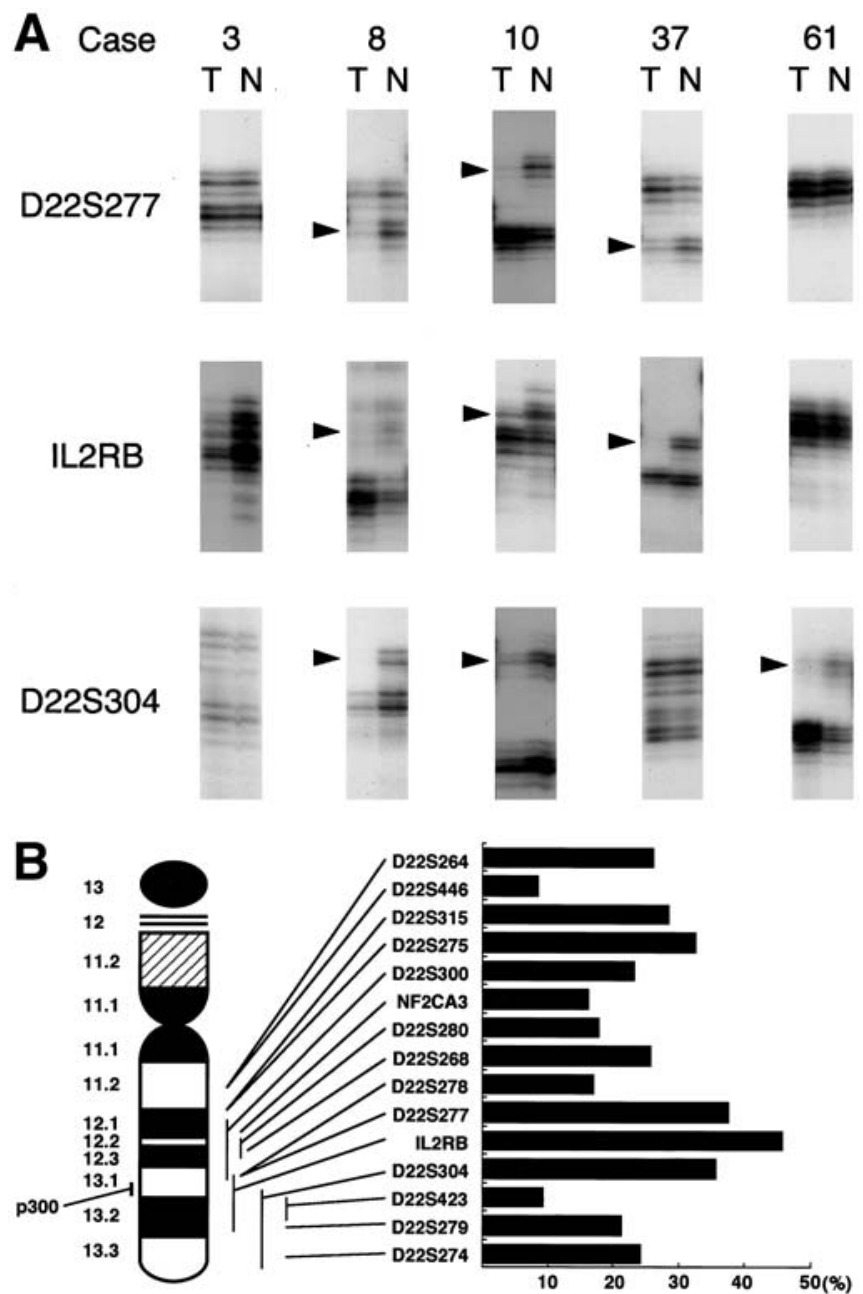

Fig. 1A,B. Evaluation of loss of heterozygosity (LOH) on chromosome $22 \mathrm{q}$ in gastric carcinoma. A LOH analysis using microsatellite markers. LOH was evaluated by comparing the electrophoresis patterns of the amplified fragments of microsatellite markers, using DNA samples of carcinomas $(T)$ and corresponding normal tissue $(N)$. LOH was defined as the loss of any band of non-neoplastic tissue in the carcinoma, such as LOHs (arrowheads) on D22S304, D22S277, and IL2RB. Cases 3, 8, 10, and 37, advanced carcinomas. Case 61, early carcinoma. B The frequency of loss of heterozygosity (LOH) on chromosome arm 22q in advanced carcinomas. A high frequency of $\mathrm{LOH}$, of more than $30 \%$, is observed on D22S275 (33\%), D22S304 (38\%), D22S277 (36\%), and IL2RB (46\%). The location of D22S304, D22S277, and IL2RB is close to the p300 gene locus on chromosome arm $22 \mathrm{q} 13$

quent $\mathrm{LOH}$ was located at the 22q13 locus containing the $p 300$ gene, which was telomeric to the NF2 gene.

\section{Clinicopathological significance of 22q13-LOH}

To clarify the significance of 22q13-LOH in the development and progression of gastric carcinoma, we further examined 20 more cases of early carcinoma
(10 diffuse and 10 intestinal type). Using three microsatellite markers, D22S304, D22S277, and IL2RB (Fig. 1), the frequency of LOH on these loci was significantly lower in the early carcinomas, at 26\% (5/19 informative cases), $15 \%(3 / 20)$, and $0 \%$, respectively, than in the advanced cases $(36 \%, 38 \%$ and $46 \%$, respectively).

When the data for the early and advanced gastric carcinomas were combined, we could evaluate the clinicopathological characteristics of the patients whose specimens showed LOH on any of the three loci of $22 q 13$ (Table 1). The frequency of 22q13-LOH was the same in the diffuse (30/46) and intestinal types (21/34). In the diffuse type, 22q13-LOH was not correlated with any of the clinicopathological factors. On the other hand, in the intestinal type, 22q13-LOH was more frequent in the carcinomas of advanced stage, showing vascular and lymphatic invasion and lymph node metastasis. As for the association with EBV, a positive signal for EBER was much more frequently observed in the diffuse type, but the frequency of $22 \mathrm{q} 13-\mathrm{LOH}$ was not significantly different in the carcinomas with or without EBV in either the intestinal or the diffuse types.

\section{Sequence analysis of $\mathrm{p} 300 \mathrm{cDNA}$}

Because p300 is located on chromosome 22q13, we evaluated the somatic mutation of the $p 300$ gene by RTPCR and SSCP techniques. The specimens examined consisted of 27 carcinomas showing 22q13-LOH (14 diffuse type and 13 intestinal type), and 6 carcinomas without $\mathrm{LOH}$ (4 diffuse and 2 intestinal type). All carcinomas were advanced ones, because of the limitation of the amount of tissue available for RNA study.

Twelve mutations were identified in ten samples (Fig. 2), consisting of four cases of diffuse type and six cases of intestinal type of gastric carcinoma (Table 2). There was no significant correlation of the mutation with clinicopathological factors such as age, sex, or location, although there was a significant correlation with the histological type.

Nine mutations were point mutations: seven were transition and two were transversion type mutations. The other three mutations were frameshift mutations, which resulted in the generation of a stop codon. Five point mutations and one frameshift mutation in cases 8 , 25, 39 and 47 were within the first and second Cys/Hisrich regions $(\mathrm{C} / \mathrm{H}-1$ and -2$)$ encoded by the $p 300$ gene. One deletion mutation, in case 37 , occurred in the bromodomain $(\mathrm{Br})$ and the two point mutations in cases 41 and 57 were within the CREB-binding domain.

Regarding alteration of the other allele, mutation of the $p 300$ gene was only identified in 1 of the 14 cases of the diffuse type of gastric carcinoma with 22q13-LOH 
Table 1. Loss of heterozygosity on chromosome 22q13 and clinicopathological factors in diffuse and intestinal types of gastric carcinoma

\begin{tabular}{|c|c|c|c|c|c|c|}
\hline \multirow[b]{2}{*}{ Clinicopathological factors } & \multicolumn{2}{|c|}{ Diffuse type } & \multirow[b]{2}{*}{$P$ value } & \multicolumn{2}{|c|}{ Intesinal type } & \multirow[b]{2}{*}{$P$ value } \\
\hline & $\mathrm{LOH}(+)$ & $\mathrm{LOH}(-)$ & & $\mathrm{LOH}(+)$ & $\mathrm{LOH}(-)$ & \\
\hline Age & $65 \pm 14$ & $64 \pm 13$ & NS & $64 \pm 7$ & $63 \pm 7$ & NS \\
\hline Sex (male/female) & $22 / 8$ & $9 / 7$ & NS & $15 / 6$ & $9 / 4$ & NS \\
\hline $\begin{array}{l}\text { Location } \\
\quad \text { (cardia/body/antrum) }\end{array}$ & $10 / 12 / 8$ & $2 / 9 / 5$ & NS & $4 / 11 / 6$ & $1 / 6 / 6$ & NS \\
\hline Early/advanced & $5 / 25$ & $5 / 11$ & NS & $3 / 18$ & $7 / 6$ & 0.0042 \\
\hline $\begin{array}{l}\text { Depth of invasion } \\
(\mathrm{m} / \mathrm{sm} / \mathrm{mp} / \mathrm{ss}, \mathrm{se}, \mathrm{si})\end{array}$ & $2 / 3 / 5 / 20$ & $3 / 2 / 2 / 9$ & NS & $2 / 1 / 0 / 18$ & $5 / 2 / 3 / 3$ & 0.0003 \\
\hline Venous invasion $(+/-)$ & $26 / 4$ & $11 / 5$ & NS & $19 / 2$ & $6 / 7$ & 0.0044 \\
\hline Lymphatic invasion $(+/-)$ & $26 / 4$ & $12 / 4$ & NS & $19 / 2$ & $8 / 5$ & 0.0426 \\
\hline Lymph node metastasis $(+/-)$ & $20 / 10$ & $10 / 6$ & NS & $17 / 4$ & $4 / 9$ & 0.0034 \\
\hline $\operatorname{EBV}(+/-)^{\mathrm{a}}$ & $10 / 20$ & $4 / 12$ & NS & $4 / 17$ & $2 / 11$ & NS \\
\hline
\end{tabular}

$\mathrm{LOH}$, loss of heterozygosity; NS, not significant; $\mathrm{m}$, intramucosal carcinoma; sm, carcinoma invading to the submucosa; mp, carcinoma invading to the submucosa; ss, carcinoma invading to the subserosa; se, carcinoma exposed on the serosal surface; si, carcinoma infiltrating to other organs ${ }^{a}$ Positive or negative signal by Epstein-Barr virus-encoded small RNA (EBER) in situ hybridization in advanced carcinoma

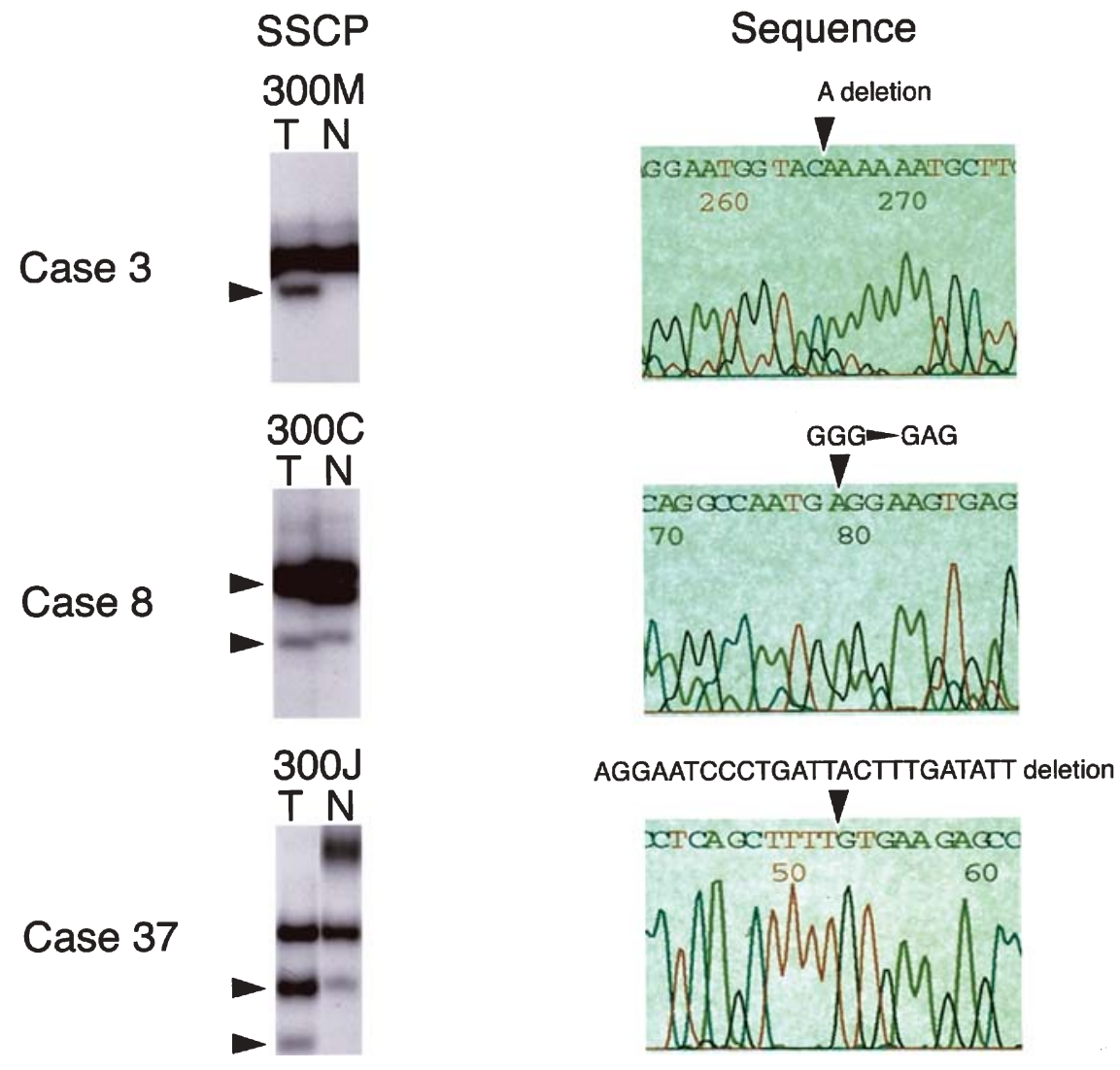

Fig. 2. Reverse transcriptase-polymerase chain reaction (RT-PCR)-singlestranded conformation polymorphism (SSCP) analysis of the $p 300$ gene. A fragment of $p 300$ gene cDNA was amplified and subjected to PCR-SSCP anaysis; $300 M$ corresponds to the region between codons 1378 and 1477 in case 3; $300 C$, region between codons 327 and 443 in case 8 ; and $300 \mathrm{~J}$, region between codons 1060 and 1173 in case 37 . The sequencing of the abnormally shifted bands (arrowheads) demonstrates 1 base-pair deletion on codon 1468 in case 3, a missense mutation, GGG to GAG (Gly to Glu), on codon 359 in case 8, and 25 base-pair deletion on codon 1084 to 1092 in case 37. $T$ and $N$ as in Fig. 1
(7\%), whereas it was observed in 6 of the 13 cases of the intestinal type with $\mathrm{LOH}(46 \%)$. In the cases without 22q13-LOH, three mutations were identified, and all of the cases with the mutation were of the diffuse type histologically. Two of the three mutations were frameshift mutations, and two of the three cases were associated with EBV infection.

\section{Discussion}

Gastric carcinoma has the same alterations of tumor suppressor genes as colorectal carcinoma, such as $A P C$ on chromosome 5q, TP53 on 17p, and DCC on 18q. In the present study, we confirmed that $\mathrm{LOH}$ on chromosome $22 \mathrm{q}$ was also observed with the same considerable 
Table 2. $p 300$ mutations in diffuse and intestinal types of gastric carcinomas

\begin{tabular}{|c|c|c|c|c|c|c|c|c|c|c|}
\hline \multirow[b]{2}{*}{ Case no. } & \multirow[b]{2}{*}{$\begin{array}{l}\text { Diffuse/ } \\
\text { Intestinal }\end{array}$} & \multirow[b]{2}{*}{ Nucleotide } & \multirow[b]{2}{*}{ Codon } & \multirow[b]{2}{*}{ Domain } & \multirow[b]{2}{*}{ Alteration } & \multirow[b]{2}{*}{ Nucleotide change } & \multirow[b]{2}{*}{$\begin{array}{l}\text { Nature of } \\
\text { the mutation }\end{array}$} & \multicolumn{3}{|c|}{ 22q13-LOH } \\
\hline & & & & & & & & IL2RB & $\mathrm{D} 22 \mathrm{~S} 304$ & $\mathrm{D} 22 \mathrm{~S} 277$ \\
\hline 8 & Diffuse & 2275 & 359 & $\mathrm{C} / \mathrm{H}-1$ & Transition & GGG $\rightarrow$ G $\underline{A G}$ & Gly $\rightarrow$ Glu & $\mathrm{LOH}$ & $\mathrm{LOH}$ & Hete \\
\hline 3 & Diffuse & 5601 & 1468 & & Deletion & One base-pair deletion & Frameshift & Hete & Hete & Hete \\
\hline 18 & Diffuse & 1804 & 202 & & Transversion & CGA $\rightarrow$ CTA & Arg $\rightarrow$ Leu & Hete & Hete & Hete \\
\hline 25 & Diffuse & $2353-2366$ & $385-389$ & $\mathrm{C} / \mathrm{H}-1$ & Deletion & 14 base-pair deletion & Frameshift & Hete & Hete & Hete \\
\hline 37 & Intestinal & $4451-4475$ & 1084-1092 & $\mathrm{Br}$ & Deletion & 25 base-pair deletion & Frameshift & $\mathrm{LOH}$ & Hete & $\mathrm{LOH}$ \\
\hline 39 & Intestinal & 5535 & 1446 & $\mathrm{C} / \mathrm{H}-2$ & Transition & $\mathrm{TAT} \rightarrow \mathrm{CAT}$ & Tyr $\rightarrow$ His & $\mathrm{LOH}$ & Hete & $\mathrm{LOH}$ \\
\hline 41 & Intestinal & 2718 & 507 & CREB & Transition & $\mathrm{GAG} \rightarrow \mathrm{GGG}$ & Glu $\rightarrow$ Gly & $\mathrm{LOH}$ & Hete & NI \\
\hline \multirow[t]{2}{*}{46} & Intestinal & 1705 & 169 & & Transition & $\mathrm{A} \underline{\mathrm{C}} \rightarrow \mathrm{A} \underline{\mathrm{T}} \mathrm{G}$ & Thr $\rightarrow$ Met & $\mathrm{LOH}$ & Hete & NI \\
\hline & & 1809 & 204 & & Transition & $\underline{\mathrm{GAT}} \rightarrow \underline{\mathrm{A}} \mathrm{AT}$ & Asp $\rightarrow$ Asn & & & \\
\hline \multirow{2}{*}{47} & Intestinal & 2247 & 350 & $\mathrm{C} / \mathrm{H}-1$ & Transition & $\overline{\mathrm{A}} \mathrm{AG} \rightarrow \mathrm{G} A G$ & Lys $\rightarrow$ Glu & $\mathrm{LOH}$ & $\mathrm{LOH}$ & Hete \\
\hline & & 2315 & 372 & $\mathrm{C} / \mathrm{H}-1$ & Transversion & $\mathrm{AAG} \rightarrow \mathrm{AAT}$ & Lys $\rightarrow$ Asn & & & \\
\hline 57 & Intestinal & 2722 & 508 & CREB & Transition & $\mathrm{A} \underline{\mathrm{A}} \overline{\mathrm{C}} \rightarrow \mathrm{A} \underline{\mathrm{G}} \overline{\mathrm{C}}$ & Asn $\rightarrow$ Ser & $\mathrm{LOH}$ & $\mathrm{LOH}$ & $\mathrm{LOH}$ \\
\hline
\end{tabular}

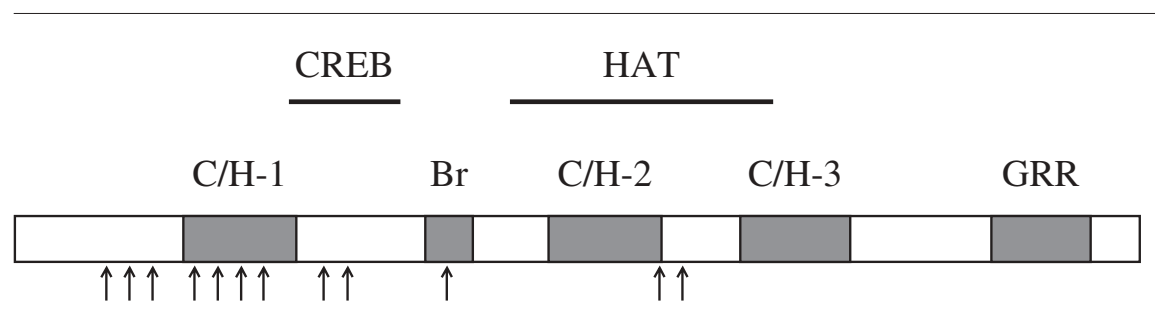

LOH, loss of heterozygosity; hete, heterozygous; NI, not informative; C/H-1,2,3; Cys/His rich regions; Br, bromodomain; GRR, glutamine-rich region; CREB, cAMP response element binding protein (CREB) binding domain; HAT, histone acetyltransferase domain

Schematic drawing of p300 molecule, showing the positions of the mutations, is represented below the table. Arrows, altered codons; hatched boxes, regions homologous to CREB-binding protein (CBP)

frequency in gastric carcinomas as in colon carcinomas [2]. A candidate for the tumor suppressor gene on chromosome $22 \mathrm{q}$ is the $p 300$ gene, because the most frequent $\mathrm{LOH}$ was located at the 22q13 locus. When we directly analyzed the $p 300$ gene mutations by RTPCR-SSCP, mutations were observed in 6 of the 13 gastric carcinomas of the intestinal type with $22 \mathrm{q} 13$ $\mathrm{LOH}$. One mutation was a frameshift mutation at codon 1084, which resulted in truncation of the encoded product before the $\mathrm{C} / \mathrm{H}-2$ (Table 2). $\mathrm{C} / \mathrm{H}-2$ is located within the histone acetyltransferase (HAT) domain, where $p 300 / \mathrm{CBP}$ also interacts with $p 53$ functioning as a coactivator for $p 53$-mediated transcription [12]. The other five mutations were missense mutations at the C/H-1 and -2, and CREB-binding domains. Thus, mutation within a functionally important region in combination with loss of another allele fits the two-hit theory of the inactivation of tumor suppressor genes. Therefore, the $p 300$ gene is the tumor suppressor gene in the intestinal type of gastric carcinoma, and this finding also illustrates that common genetic alterations underlie colorectal carcinoma and the intestinal type of gastric carcinoma.

$\mathrm{LOH}$ on chromosome $22 \mathrm{q}$ was observed mainly in the late stage of colorectal carcinomas, correlating with lymph node metastasis [20]. In the intestinal type of gastric carcinoma, 22q13-LOH was more frequently observed in the advanced stage, accompanied by vascular and lymphatic invasion, and lymph node metastasis.
Thus, the inactivation of $p 300$ may be involved in the progression of gastric carcinoma, facilitating metastasis via vascular and lymphatic invasion. This may be related to the function of $p 300$ other than that of histone acetyl transferase, that is, the activation of a major adhesion molecule, $\beta 1$ integrin, by interacting with the nuclear protooncoprotein SYT [21]. It is also interesting to note that there were two cases that showed two different mutations in the same tumor tissue. This also suggests that the inactivation of p300 is a late genetic event in the subpopulation of the intestinal type of gastric carcinoma.

In the diffuse type of gastric carcinoma, the frequency of 22q13-LOH was similar to that in the intestinal type, but $p 300$ gene mutation was rare in the carcinomas with $\mathrm{LOH}$. Furthermore, in contrast to findings in the intestinal type, 22q13-LOH was not correlated with any of the clinicopathological factors. Therefore, the significance of $p 300$ gene alteration in the diffuse type is apparently different from that in the intestinal type. Because two of the three mutations were frameshift mutations in the diffuse type without $22 \mathrm{q}-\mathrm{LOH}$, the alteration on at least one allele of the $p 300$ gene may be more ubiquitous in the diffuse type. Therefore, when combined with other alterations, such as homozygous deletion, promoter methylation, and EBV infection, inactivation of $p 300$ may occur along the carcinogenesis of the diffuse type of gastric carcinoma. Mouse embryonic cells (MEC) with a $p 300+/-$ genotype showed defec- 
tiveness in adhesion to fibronectin-coated surfaces in comparison with the wild type, suggesting that failure to form a sufficient quantity of SYT/p300 complexes leads to a major defect in cell adhesion/spreading [21]. In addition to the example of Rubinstein Taybi syndrome in humans, mice with monoallelic inactivation of the $C B P$ gene show an increased incidence of hematological malignancies [22]. Thus, $p 300$ gene alteration, even on one allele (haploinsufficiency), may be involved in the development of the carcinoma. Knock-down experiments, using RNA interference, may clarify the role of p300 in gastric cancer.

In conclusion, p300 gene alteration may play an important role in both the intestinal type and the diffuse type of gastric carcinoma, but the significance of the alterations in each type is different. Mutation within a functionally important region, in combination with loss of one allele, suggests that the p300 gene is the tumor suppressor gene in the intestinal type of gastric carcinoma, as it is in colorectal carcinoma. On the other hand, in the diffuse type, the $p 300$ gene is not a classical suppressor gene, but further study is necessary to find other mechanisms of p300 inactivation and to clarify the functional role of p300 in cell adhesion/ spreading.

\section{References}

1. Fenoglio-Preiser C, Carneiro F, Correa P, Guilford P, Lambert R, Megraud F, et al. Gastric carcinoma. In: Hamilton SR, Aaltonen LA, editors. Pathology and genetics of tumours of the digestive system. Lyon: IARC; 2000. pp 39-52.

2. Miyaki M, Seki M, Okamoto M, Yamanaka A, Maeda Y, Tanaka $\mathrm{K}$, et al. Genetic changes and histopathological types in colorectal tumors from patients with familial adenomatous polyposis. Cancer Res 1990;50:7166-73.

3. Tamura G. Molecular pathogenesis of adenoma and differentiated adenocarcinoma of the stomach. Pathol Int 1996;46:834-41.

4. Trofatter JA, MacCollin MM, Rutter JL, Murrell JR, Duyao MP, Parry DM, et al. A novel moesin-, ezrin-, radixin-like gene is a candidate for the neurofibromatosis 2 tumor suppressor. Cell 1993;72:791-800.

5. Eckner R, Ewen ME, Newsome D, Gerdes M, DeCaprio JA, Lawrence JB, et al. Molecular cloning and functional analysis of the adenovirus E1A-associated $300-\mathrm{kD}$ protein (p300) reveals a protein with properties of a transcriptional adaptor. Genes Dev 1994;8:869-84.

6. Bianchi AB, Hara T, Ramesh V, Gao J, Klein-Szanto AJ, Morin $\mathrm{F}$, et al. Mutations in transcript isoforms of the neurofibromatosis
2 gene in multiple human tumour types. Nature Genet 1994; 6:185-92.

7. Arakawa H, Hayashi N, Nagase H, Ogawa M, Nakamura Y. Alternative splicing of the NF2 gene and its mutation analysis of breast and colorectal cancers. Hum Mol Genet 1994;3:56568.

8. Fukasawa T, Chong JM, Sakurai S, Koshiishi N, Ikeno R, Tanaka A, et al. Allelic loss of $14 \mathrm{q}$, and 22q, NF2 mutation, and genetic instability occur independently of c-kit mutation in gastrointestinal stromal tumor. Jpn J Cancer Res 2000;91:1241-9.

9. Giles RH, Peters DJM, Breuning MH. Conjunction dysfunction: CBP/p300 in human disease. Trends Genet 1998;14:178-83.

10. Arany Z, Sellers WR, Livingston DM, Eckner R. E1A-associated p300 and CREB-associated CBP belong to a conserved family of coactivators. Cell 1994;77:799-800.

11. Ogryzko VV, Schiltz RL, Russanova V, Howard BH, Nakatani Y. The transcriptional coactivators p300 and CBP are histone acetyltransferases. Cell 1999;87:953-9.

12. Gu W, Roeder RG. Activation of p53 sequence-specific DNA binding by acetylation of the p53 C-terminal domain. Cell 1997; 90:595-606.

13. Muraoka M, Konishi M, Kikuchi-Yanoshita R, Tanaka K, Shitara $\mathrm{N}$, Chong JM, et al. p300 gene alterations in colorectal and gastric carcinomas. Oncogene 1996;12:1565-9.

14. Gayther SA, Batley SJ, Linger L, Bannister A, Thorpe K, Chin $\mathrm{SF}$, et al. Mutations truncating the EP acetylase in human cancers. Nature Genet 2000;24:300-3.

15. Petrij F, Giles RH, Dowerse HG, Saris JJ, Hennekam RCM, Masuno M, et al. Rubinstein-Taybi syndrome caused by mutations in the transcriptional coactivator CBP. Nature 1995;376: 348-51.

16. The Japanese Research Society for Gastric Cancer. Japanese classification of gastric carcinoma. 1st English Ed. Tokyo: Kanehara; 1995.

17. Laurén P. The two histological main types of gastric carcinoma. Diffuse and so-called intestinal type carcinoma. An attempt at histoclinical classification. Acta Pathol Microbiol Scand 1965; 64:31-49.

18. Fukayama M, Hayashi Y, Iwasaki Y, Chong JM, Ooba T, Takizawa T, et al. Epstein-Barr virus-associated gastric carcinoma and Epstein-Barr virus infection of the stomach. Lab Invest 1994; 71:73-81.

19. Koshiishi N, Chong JM, Fukasawa T, Ikeno R, Tanaka A, Kanazawa K, et al. Microsatellite instability and loss of heterozygosity in primary and secondary proliferative lesions of the parathyroid gland. Lab Invest 1999;79:1051-8.

20. Iino H, Fukayama M, Maeda Y, Koike M, Mori T, Takahashi T, et al. Molecular genetics for clinical management of colorectal carcinoma. 17p, 18q, and 22q loss of heterozygosity and decreased DCC expression are correlated with the metastatic potential. Cancer 1994;73:1324-31.

21. Eld E, Kung AL, Scully R, Livingstone DM. p300 interacts with the nuclear proto-oncoprotein SYT as part of the active control of cell adhesion. Cell 2000;102:839-48.

22. Kung AL, Rebel VI, Bronson RT, Ch'ng LE, Sief CA, Livingstone DM, et al. Gene dose-dependent control of hematopoiesis and hematologic tumor suppression by CBP. Genes Dev 2000;14:272-7. 